Revista Brasileira de Farmacognosia Brazilian Journal of Pharmacognosy 22(2): 428-435, Mar./Apr. 2012

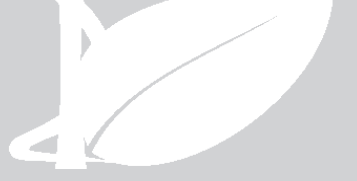

Article

Received 14 May 2011

Accepted 3 Aug 2011

Available online 9 Jan 2012

Keywords:

Adenanthera pavonina

diabetic neuropathy

superoxide anion

tail-flick latency

total calcium

ISSN 0102-695X

http://dx.doi.org/10.1590/S0102-

695X2012005000008

\section{Attenuating effect of seeds of Adenanthera pavonina aqueous extract in neuropathic pain in streptozotocin-induced diabetic rats: an evidence of neuroprotective effects}

\author{
Ramdas B. Pandhare, ${ }^{* 1,3}$ B. Sangameswaran, ${ }^{2}$ Popat B. Mohite, ${ }^{1}$ \\ Shantaram G. Khanage1
}

${ }^{\prime} M E S$ College of Pharmacy, Sonai, Newasa, Ahmednagar, India,

${ }^{2}$ Adesh Institute of Pharmacy and Biomedical Sciences, Bathinda, Punjab,

${ }^{3}$ Department of Pharmacy, Suresh Gyan Vihar University, Jaipur, India.

\begin{abstract}
The aim of present study was to investigate the attenuating effects of Adenanthera pavonina L., Leguminosae-Mimosaceae seeds aqueous extract (APSAE), in streptozotocin (STZ)-induced diabetic neuropathy in rats. APSAE (50, 100 and 200 $\mathrm{mg} / \mathrm{kg}$ per day) was given to diabetic rats for twelve weeks. Cold and hot water tail immersion tests, photoactometer and Rota-rod tests were performed to assess degree of colder, thermal, spontaneous motor activity and motor co-ordination changes respectively at different time intervals $i$.e., week $0,4,8$ and 12 . Tissue superoxide anion and total calcium levels were determined after twelve weeks to assess biochemical alterations. Histopathological evaluations of sciatic nerve were also performed to assess nerve damage. APSAE treatment increased tail flick latency significantly in diabetic rats. APSAE also reduced superoxide anion and total calcium levels. These results suggested that APSAE has attenuated development of diabetic neuropathy in streptozotocin-induced diabetic rats when compared with pregabalin $(10 \mathrm{mg} / \mathrm{kg}$, p.o. $)$ and could be beneficial in preventing the progression of diabetic nephropathy.
\end{abstract}

\section{Introduction}

Neuropathy is a common and costly complication of both type 1 (T1DM) and type 2 diabetes (T2DM). The prevalence of neuropathy is estimated to be about $8 \%$ in newly diagnosed patients and greater than $50 \%$ in patients with long-standing disease (Boulton et al., 2005). An estimated $15 \%$ of all patients with diabetes will develop foot ulcers (Gordois et al., 2003), and diabetic neuropathy is the leading cause of nontraumatic limb amputation (Thomas et al., 1999). In recent years, considerable progress has been made toward understanding the biochemical mechanisms leading to diabetic neuropathy, and as a result, new treatment modalities are being explored.

Pain after injury to the nervous system (neuropathic pain) is a major chronic pain condition that remains difficult to treat. Both peripheral and central mechanisms of neuropathic pain have been proposed by various researchers (Carlton et al., 2009; Muthuraman et al., 2010a). Neuropathic pain associated with peripheral nerve injury is characterized by the sensory abnormalities such as unpleasant abnormal sensation (dysesthesia), an increased response to painful stimuli (hyperalgesia), and pain in response to a stimulus that does not normally provoke pain (allodynia) (Woolf \& Mannion, 1999). Peripheral neuropathic pain is frequently observed in patients with long standing diabetes, cancer, AIDS, leprosy, cervical disc protrusion and foraminotomy and after surgery (Alston \& Pechon, 2005; Garg et al., 2010; Shaladi et al., 2009; Weisz et al, 2010). Chronic constriction injury of sciatic nerve induced painful neuropathy is a widely employed model for induction of neuropathic pain in experimental animals (Bennett \& Xie, 1988). Conventional analgesics like non-steroidal anti-inflammatory drugs and opioids are ineffective clinically in attenuating neuropathic pain. Further, tricyclic anti-depressants (i.e., amitriptyline, nortriptyline and imipramine) and anti-convulsants (i.e., phenytoin, carbamazepine, gabapentin, lamotrigine and topiramate) have also been reported to produce antiallodynic effects in neuropathy (Lee et al., 2000; Dwight, 2006). However, these drugs are reported to exhibit a wide spectrum of adverse effects which limit their full clinical exploitation in management of painful neuropathy (Carol \& Jane 2006; Hama et al., 2010). Moreover, none of the medications assessed in randomized controlled studies conducted has been found effective in Complex Regional Pain Syndrome i.e. CRPS (Kumar et al., 2007; Thomson \& Jacques, 2009). Preclinically, various studies have 
reported herbal medicine to produce the beneficial effect in the management of painful neuropathy i.e., Aconiti tuber, Lindera angustifolia, Teucrium polium, Phyllanthus emblica, Vochysia divergens, Cannabis sativa, Nigella sativa, Ocimum sanctum and Ginkgo biloba (Comelli et al., 2008; Kanter, 2008; Kim et al., 2009; Muthuraman et al., 2008a; Wirth et al., 2005). Therefore, there is an ample scope of new medicine from plant origin to combat the neuropathic pain conditions. Some recent clinical reports have also advocated beneficial effect of drugs from plant origin in neuropathic pain conditions (Babbar et al.,2009; Ellis et al.,2009; Nurmikko et al., 2007).

Adenanthera pavonina L., LeguminosaeMimosaceae, is a deciduous tree, 18-24 m tall, bole erect and $60 \mathrm{~cm}$ in diameter. Many species of Adenanthera, including $A$. pavonina, have been used as traditional herbal medicine against a variety of diseases. The plant is reported to have a wide range of biological activities, such as astringent and styptic (used in diarrhoea, haemorrhage from the stomach, haematuria), antiinflammatory (in rheumatic affections, gout). Seeds are used as anticephalgic and also used for the treatment of paralysis. The seeds contains an anti-inflammatory active principle, $O$-acetylethanolamine. The leaves contain octacosanol, dulcitol, glucosides of $\beta$-sitosterol and stigmasterol. The bark contains stigmasterol glucoside (Khare, 2007). Traditionally, the ground seed is widely used for the treatment of various human ailments such as treatment of boils, inflammation, blood disorders, arthritis, rheumatism, cholera, paralysis, epilepsy, convulsion, spasm and indigestion (Burkill, 1966; Balogun \& Fetuga, 2004). Phytochemically, the seed and its pod contain glycosides, saponins and steroids (Howes, 1974; Yadav et al., 1976). A new five-membered lactone ring compound, parvonin was isolated from the methanol soluble part of $A$. pavonina oil extracted from the seed has been reported to have membrane-stabilizing activity by reducing lytic effect on erythrocytes, exhibited by many intravenous drugs (Muhammad et al., 2005; Anna et al., 2006). The methanol seed extract has also been reported to demonstrate anti-inflammatory and analgesic activities (Olajide et al., 2004). However,usefulness of Adenanthera pavonina in stz-induced diabetic painful peripheral neuropathy remains to be explored. Therefore, the present study has been designed to investigate the ameliorative effect of Adenanthera pavonina in neuropathic pain in streptozotocin-induced diabetic rats.

\section{Material and Methods}

\section{Collection of plant material}

Dry seeds of Adenanthera pavonina L., Leguminosae-Mimosaceae, were collected during March 2009 from the Mahatma Phule Krishi Vidyapeeth, Rahuri,
Maharashtra, India. The leaves were identified by Dr. P.G. Diwakar, Joint Director, Botanical Survey of India, Pune. A voucher specimen (BSI/WRC/Tech/2010/463) has been kept in herbarium, in Botanical Survey of India, Pune Maharashtra.

\section{Chemicals}

Streptozotocin (STZ) was purchased from Sigma chemical company, Bangalore. All other chemicals used in the experiments were purchased locally (Merck and S D fine Chemicals) and were of analytical grade.

\section{Preparation of aqueous extract}

The powdered seed material was macerated with distilled water for $48 \mathrm{~h}$ at room temperature with occasional stirring. It was then filtered through whatmann filter paper. The filtrate was air dried and stored in refrigerator for further use as an APSAE. (Adenanthera pavonina seed aqueous extract). The yield of the extract was $2.5 \%(\mathrm{w} / \mathrm{w})$. During experiment the crude extract was diluted with distilled water just before administration to animals (Jain, 1968; Gupta et al., 2004 ).

\section{Induction of diabetes}

Diabetes was induced in male Wistar albino rats aged 2-3 months (180-200 g body weight) by intraperitoneal administration of STZ (single dose of 55 $\mathrm{mg} / \mathrm{kg} \mathrm{b.w.)} \mathrm{dissolved} \mathrm{in} \mathrm{freshly} \mathrm{prepared} 0.01 \mathrm{M}$ citrate buffer, pH 4.5 (Sharma et al., 2008) after $72 \mathrm{~h}$ rats with marked hyperglycemia (fasting blood glucose $\geq 250 \mathrm{mg}$ / dl) were selected and used for the study. All the animals were allowed free access to tap water and pellet diet and maintained at room temperature in plastic cages, as per the guidelines of Institutional Animal Ethics committee of M.E.S.College of pharmacy (MESCOP/IAEC/07/2010).

\section{Experimental design}

To investigate the effects of APSAE, the animals were divided into six groups each consisting of six animals:

Group 1: Untreated normal rats

Group 2: Untreated diabetic rats

Group 3: Diabetic rats treated with pregabalin 10 $\mathrm{mg} / \mathrm{kg} \mathrm{b.w}$

Group 4: Diabetic rats treated with $50 \mathrm{mg}$ APSAE/ kg b.w.

Group 5: Diabetic rats treated with $100 \mathrm{mg}$ APSAE/kg b.w.

Group 6: Diabetic rats treated with $200 \mathrm{mg}$ APSAE/kg b.w.

After an overnight fast, APSAE suspended in 
distilled water was fed to the Group 4, 5 and 6 rats by gastric intubation using a force feeding needle.Group 1 and 2 rats were fed with water alone. Group 3 rats were fed with standard drug pregabalin a day orally daily upto twelve weeks.

\section{Behavioural studies}

Cold and hot water immersion tests

Cold and hot water immersion tests were carried out according to the method described by Sharma et al. (2008). In the cold immersion test, the tail of the rat was immersed in cold water maintained at $10{ }^{\circ} \mathrm{C}$, while in the hot water immersion test; the tail was immersed in hot water maintained at $52{ }^{\circ} \mathrm{C}$. In both tests, basal tail flick latency (withdrawal response of tail) or signs of struggle were observed. The cut off time was $15 \mathrm{~s}$. Cold and hot immersion tests were carried out at 0, 4, 8 and 12 weeks in normal and streptozotocin diabetic untreated and treated rats and changes in tail flick latency in all groups were compared with standard drug pregabalin.

\section{Motor co-ordination test}

Motor co-ordination (grip muscle strength) was evaluated by a Rota-rod device as described by Jones \& Roberts (1968) with slight modification of Muthuraman et al. (2008b). Rats were placed for $1 \mathrm{~min}$ on the rotating rod (25 rpm). The time taken for the falling from the roller, during one minute period was recorded.

Spontaneous locomotor (exploratory) activity test

Photoactometer test was employed to assess the effect of drug treatment on spontaneous motor (exploratory) activity. Each animal was observed for a period of $5 \mathrm{~min}$ in a square closed field arena $(30 \times 30 \times 30 \mathrm{~cm})$ equipped with six photocells in the outer wall. Interruptions of photocell beams (locomotor/exploratory action) were recorded by means of a six digits counter (Goddard et al., 2008).

\section{Biochemical estimation}

All the animals were sacrificed after twelve weeks of treatment after stz-induced diabetes with chemical euthanasia (50 mg/kg, i.p., thiopental sodium). The sciatic nerve and the tissue beneath the sciatic nerve were isolated immediately. Further, the samples were kept in the humidity chamber (maintained at $85 \%$ relative humidity and $37{ }^{\circ} \mathrm{C}$ temperature) to remove and maintain the moisture content of the collected samples. The sciatic nerve homogenate $(10 \%, \mathrm{w} / \mathrm{v})$ was prepared with $0.1 \mathrm{M}$ Tris- $\mathrm{HCl}$ buffer ( $\mathrm{pH} 7.4$ ), and deionised water for total protein and total calcium estimation respectively. Superoxide anion measurement was carried out in sciatic nerve as described method of Wang et al. (1998). Protein concentration was estimated according to the method of Lowry et al. (1951), using Bovine serum albumin (BSA) as a standard. The absorbance was determined spectrophotometrically at 750 nm.

\section{Estimation of superoxide anion generation}

The sciatic nerve superoxide anion generation was estimated in terms of reduced nitroblue tetrazolium (NBT) as described in the method of Wang et al. (1998). Briefly, sciatic nerve homogenate react with NBT under certain chemical environment to form formazan as an index of superoxide anion generation. The absorbance of formazan was determined spectrophotometrically at 540 nm.

The quantity of NBT reduction $=\mathrm{A} \times \mathrm{V} /(\mathrm{T} \times \mathrm{Wt} \mathrm{x}$ $\varepsilon \times 1)$,

Where, A-The absorbance of blue formazan at $540 \mathrm{~nm}, \mathrm{~V}-\mathrm{The}$ volume of the solution, T-The time period (90 min) during which rings were incubated with NBT, Wt-The blotted wet weight of the sciatic nerve, $\varepsilon$-The extinction coefficient of blue formazan (i.e., $0.72 \mathrm{1} / \mathrm{mmol} /$ $\mathrm{mm})$, 1-The length of the light path.

Results were reported as picomoles per minute per milligram wet weight of sciatic nerve.

\section{Estimation of total calcium}

Total calcium levels were estimated in sciatic nerve according to the method of Severinghaus \& Ferrebee (1950) with slight modification of Muthuraman et al., (2008a). Briefly, sciatic nerve homogenate was mixed with $1 \mathrm{~mL}$ of trichloroacetic acid (4\%) in ice cold conditions and centrifuged at $2000 \mathrm{x} g$ for $10 \mathrm{~min}$. The clear supernatant was used for the estimation of total calcium ion by atomic emission spectroscopy at $556 \mathrm{~nm}$.

\section{Histopathological evaluation}

Samples of distal portion of sciatic nerve were stored in the fixative solution (10\% formalin) and cut into $4 \mu \mathrm{m}$ thickness. Staining was done by using hematoxylin and eosin as described by method of Sudoh et al. (2004). Nerve sections were analyzed qualitatively under light microscope (450x) for axonal degeneration.

\section{Statistical analysis}

The results were expressed as mean \pm SEM. The statistical analysis was carried out by using Graph Pad Instate version 5. Statistical difference was tested by using one-way analysis of variance (ANOVA) followed 
by Dunnette's multiple comparison test. A difference in the mean $p$ value $<0.05$ was considered as statistically significant.

\section{Results}

\section{Cold water immersion test}

In STZ-induced diabetic rats during twelve weeks of treatment, the effect of APSAE on tail flick latency in all the experimental groups of rats were studied at $0,4,8$ and 12 weeks by cold water tail-immersion test. The tail flick latency was significantly decreased in the untreated diabetic rats compared to those in normal rats. Treatment of the diabetic rats with pregabalin, APSAE 50,100 and $200 \mathrm{mg} / \mathrm{kg}$ produced a significant increase in tail flick latency when compared with diabetic untreated rats (Table 1).

\section{Hot water immersion test}

In STZ-induced diabetic rats during twelve weeks of treatment, the effect of aqueous extract on tail flick latency in all the experimental groups of rats were studied at $0,4,8$ and 12 weeks by hot water tail- immersion test. The tail flick latency was significantly decreased in the untreated diabetic rats compared to those in normal rats. Treatment of the diabetic rats with pregabalin, APSAE
50,100 and $200 \mathrm{mg} / \mathrm{kg}$ produced a significant increase in tail flick latency when compared with diabetic untreated rats (Table 2).

Motor co-ordination test and spontaneous locomotor (exploratory) activity test

Treatment of the diabetic rats with the APSAE $(50,100$ and $200 \mathrm{mg} / \mathrm{kg}$, p.o.) for twelve weeks did not produced any significant effect on motor coordination and spontaneous motor (locomotor or exploratory) activity of rats as tested on Rota-rod and photoactometer respectively (data not shown).

\section{Biochemical estimation}

After twelve weeks of treatment, stz-induced diabetic untreated rats showed a significant increase in the levels of superoxide anion and total calcium in sciatic nerve as compared to normal group. Administration of APSAE $(50,100$ and $200 \mathrm{mg} / \mathrm{kg}$, p.o.) significantly attenuated diabetes induced increase in the levels of superoxide anion and total calcium levels, in a dose dependent manner. Treatment of pregabalin also produced similar effects on superoxide anion generation However; the vehicle administration did not modulate any alteration in the superoxide anion generation and the total calcium levels (Table 3 ).

Table 1. Effect of aqueous extract of Adenanthera pavonina Linn. seed on normal and diabetic rats (cold water tail immersion test)

\begin{tabular}{clcccc}
\hline \multirow{2}{*}{ Group } & & \multicolumn{4}{c}{ Changes in tail flick latency in sec at weeks } \\
\cline { 3 - 6 } & & 0 & 4 & 8 & 12 \\
\hline I & Normal control & $4.50 \pm 0.22$ & $4.83 \pm 0.16$ & $4.66 \pm 0.21$ & $4.50 \pm 0.22$ \\
II & Diabetic control & $4.66 \pm 0.33$ & $8.33 \pm 0.21$ & $11.66 \pm 0.21$ & $14.83 \pm 0.11$ \\
III & Diabetic+pregabalin & $4.33 \pm 0.21$ & $6.50 \pm 0.22^{* *}$ & $8.50 \pm 0.22^{* *}$ & $6.83 \pm 0.30^{* *}$ \\
IV & Diabetic+aq. extract & $4.16 \pm 0.16$ & $7.33 \pm 0.21^{* *}$ & $9.33 \pm 0.21^{* *}$ & $7.33 \pm 0.21^{* *}$ \\
V & Diabetic+aq. extract & $4.66 \pm 0.21$ & $7.16 \pm 0.16^{* *}$ & $9.16 \pm 0.16^{* *}$ & $7.16 \pm 0.16^{* *}$ \\
VI & Diabetic+aq. extract & $4.83 \pm 0.16$ & $7.16 \pm 0.16^{* *}$ & $8.83 \pm 0.16^{* *}$ & $6.83 \pm 0.16^{* *}$ \\
\hline${ }^{*}<0.05 ; * * p<0.01$ values are mean \pm SEM; $\mathrm{n}=6$, when compared with diabetic control by using one way ANOVA followed by Dunnette's multiple \\
comparison test.
\end{tabular}

Table 2. Effect of aqueous extract of Adenanthera pavonina seed on normal and diabetic rats. (Hot water tail immersion test).

\begin{tabular}{clcccc}
\hline \multirow{2}{*}{ Group } & & \multicolumn{4}{c}{ Changes in tail flick latency in sec at weeks } \\
\cline { 3 - 6 } & & 0 & 4 & 8 & 12 \\
\hline I & Normal control & $5.16 \pm 0.30$ & $5.00 \pm 0.25$ & $4.50 \pm 0.22$ & $4.33 \pm 0.21$ \\
II & Diabetic control & $8.33 \pm 0.33$ & $10.16 \pm 0.30$ & $12.16 \pm 0.16$ & $14.50 \pm 0.22$ \\
III & Diabetic+pregabalin & $8.16 \pm 0.16$ & $9.00 \pm 0.25^{*}$ & $9.83 \pm 0.16^{* *}$ & $7.16 \pm 0.40^{* *}$ \\
IV & Diabetic+aq. extract & $8.50 \pm 0.20$ & $9.16 \pm 0.16$ & $10.33 \pm 0.21^{* *}$ & $7.66 \pm 0.33^{* *}$ \\
V & Diabetic+aq. extract & $8.16 \pm 0.30$ & $9.50 \pm 0.34$ & $10.16 \pm 0.16^{* *}$ & $7.33 \pm 0.33^{* *}$ \\
VI & Diabetic+aq. extract & $7.83 \pm 0.30$ & $8.83 \pm 0.40^{*}$ & $9.83 \pm 0.16^{* *}$ & $7.50 \pm 0.34^{* *}$ \\
\hline
\end{tabular}

$*_{p}<0.05 ; * * p<0.01$ values are mean \pm SEM; $\mathrm{n}=6$, when compared with diabetic control by using one way ANOVA followed by Dunnette's multiple comparison test. 
Table 3. Effect of aqueous extract of Adenanthera pavonina seed on normal and diabetic rats. (Biochemical estimation).

\begin{tabular}{clcc}
\hline Group & \multicolumn{1}{c}{ Treatment $(\mathrm{n}=6)$} & Reduction of NBT pmol $/ \mathrm{min} / \mathrm{mg}$ of protein & Total calcium pppm/mg of protein \\
\hline I & Normal control & $3.50 \pm 0.02$ & $3.91 \pm 0.02$ \\
II & Diabetic control & $22.16 \pm 0.30$ & $36.48 \pm 0.41$ \\
III & Diabetic+pregabalin & $5.13 \pm 0.13 * *$ & $5.15 \pm 0.12^{* *}$ \\
IV & Diabetic+aq. extract & $6.95 \pm 0.07 * *$ & $10.51 \pm 0.21^{* *}$ \\
V & Diabetic+aq. extract & $5.86 \pm 0.07 * *$ & $8.91 \pm 0.13^{* *}$ \\
VI & Diabetic+aq. extract & $5.78 \pm 0.08^{* *}$ & $7.91 \pm 0.10^{* *}$ \\
\hline${ }_{p}<0.05 ; * * p<0.01$ values are mean $\pm \mathrm{SEM} ; \mathrm{n}=6$, when compared with diabetic control by using one way ANOVA followed by Dunnette's multiple \\
comparison test.
\end{tabular}

\section{Histopathological evaluation}

After twelve weeks of treatment, stzinduced diabetic untreated rats resulted in significant histopathological changes assessed in transverses section of the sciatic nerve. In transverse section nerve derangement, axonal swelling, increase in number of Schwann and satellite cells were also noted. Administration of the pregabalin, APSAE (50, 100 and $200 \mathrm{mg} / \mathrm{kg}$, p.o.) significantly attenuated fiber derangement, swelling of nerve fiber and activation of neuroglial cell (satellite cells and Schwann cells) as marker of histopathological alterations (Figure 1A-F).

\section{Discussion}

In the present study, Adenanthera pavonina L., Leguminosae-Mimosaceae, attenuated sciatic nerve induced behavioural i.e., thermal and colder (hyperalgesia and allodynia), biochemical (superoxide anion and total calcium) and histopathological (axonal degeneration) changes. However no significant effect on motorcoordination and spontaneous (locomotor or exploratory) motor activity was observed. The behavioural alterations started on $3^{\text {rd }}$ day after the stz-induced diabetes in rats and lasted throughout the experimental period. These observations are in line with our earlier findings and reports from the other laboratories (Cui et al., 2000). In response to an injury to a nerve, initial steps of inflammatory reactions, involve the release of proinflammatory mediators from the resident macrophages, Schwann cells and area adjacent to nerve lesion (Marchand et al., 2005). Neuropathic pain (including CCI of sciatic nerve) has been demonstrated to produce a rise in tissue total calcium levels (Jain et al., 2009). Calcium ion accumulation has been documented to trigger the secondary messengers i.e., activation of calcium binding protein (calpain and calmodulin) and calcium dependent kinase and phosphatase action. It can alter the homeostasis function of nervous system and enhancement of auto destruction including long term potentiation, long term depression and neuronal hyperexcitation (Young, 1992). Calcium induced activation of calpains has been shown to be responsible for the axonal degeneration by alteration of stability of axonal cytoskeleton protein (Glass et al., 2002). Several studies evidenced that free radical and calcium mediated oxidative stress and inflammation together play a major role in the pathogenesis of neurodegenerative diseases, such as amyotrophic lateral sclerosis, Alzheimer's disease, Parkinson's disease and neuropathic pain (Muthuraman et al., 2010b; Gao et al., 2007). Moreover, reactive oxygen and nitrogen species have also been well documented to contribute in the pathophysiological changes in long standing diabetes, toxin, Freund's adjuvant induced inflammation, chronic constriction injury and axotomy of sciatic nerve and ischemia-reperfusion of femoral artery mediated neuropathic pain (Otto et al., 2003). In the present study, APSAE has been observed to attenuate behavioural, biochemical as well as histopathological changes. Adenanthera pavonina is reported to exert a battery of beneficial effects in various ailments viz; inflammation, blood disorders, arthritis, rheumatism, cholera, paralysis, epilepsy, convulsion, spasm and indigestion. On the basis of data in hand and with support from literature, therefore, it may be proposed that APSAE produced ameliorative effect in stz-induced diabetic painful peripheral neuropathy which may be attributed to its multiple effects viz; antioxidative and neuroprotective actions manifested in the terms of alleviation of behavioural (hyperalgesia and allodynia), biochemical (superoxide anions and total calcium activity) as well as histopathological changes. Pregabalin [(S)-3-(aminomethyl)-5-methylhexanoic acid or $S$-(+)-isomer of 3 -isobutyl $\gamma$-aminobutyric acid] is an anti-convulsant that successfully treats many neuropathic pain syndromes. Pregabalin is a Selective Cav 2.2 (a2- $\delta$ subunit) channel antagonist. It has potential actions like predecessor gabapentin, it's a structural analogue (but not functional) of the gamma aminobutyric acid. Pregabalin has analgesic, anti-convulsant and anxiolytic activities (Kumar et al., 2010). Preclinical trials have demonstrated an anti-hyperalgesic and anti-allodynic effect of pregabalin in various animal models of neuropathic pain (Bender et al., 2010; Park et al., 2010). Data of our study also supports these reports. Since pregabalin is well documented to exert 

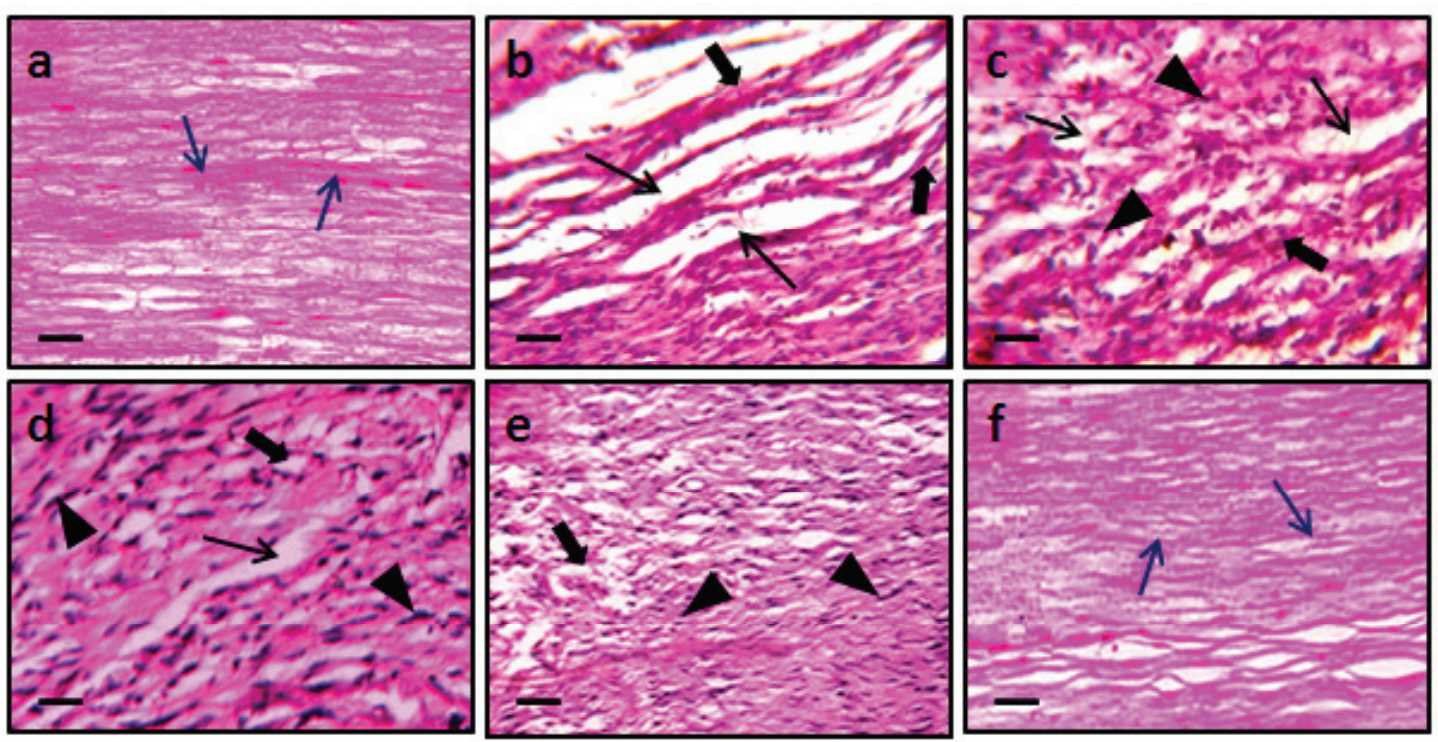

Figure 1. Effect of Adenanthera pavonina on sciatic nerve histopathological changes in stz-induced diabetes. $1 \mathrm{~A}-\mathrm{F}$ shows transverse-section of sciatic nerve of normal, Diabetic control, Diabetic treated with APSAE $(50,100$ and $200 \mathrm{mg} / \mathrm{kg})$ and pregabalin pretreated groups respectively. A and F: blue arrow shows normal fiber arrangement; B and E: black arrows show fiber derangement (thin arrow), swelling (bold arrow) of nerve fiber and presence of activated satellite cells and Schwann cells (arrow head). D and F: shows attenuation of stz-induced swelling of sciatic nerve fibers by APSAE $(50,100 \mathrm{and} 200 \mathrm{mg} / \mathrm{kg}) \mathrm{and}$ pregabalin pretreatment groups respectively. Microscopic examinations were performed under $450 \times$ light microcopy, scale bar $35 \mu \mathrm{m}$.

its beneficial effect in neuropathic pain via inhibition of voltage gated calcium [Cav 2.2 (a2- $\delta$ subunit)] channels and therefore, it is proposed that potential anti-oxidative and neuroprotective actions of Adenanthera pavonina may be an important factor in attenuating stz-induced diabetic peripheral neuropathic pain. Nevertheless further studies are needed to substantiate these findings.

\section{Acknowledgements}

The authors sincerely thank to Principal, MES College of Pharmacy, Prashant Patil Gadakh Secretory, Mula Education Society, Sonai and Department of Pharmacy, Suresh Gyan Vihar University, Jaipur, Rajasthan, India, for encouragement and availing of the laboratory facilities during the course of investigation.

\section{References}

Alston RP, Pechon P 2005. Dysaesthesia associated with sternotomy for heart surgery. Br J Anaesth 95: 153-158.

Anna J, Robert Z, Arkadiusz K 2006. Emulsions of oil from Adenanthera pavonina L. seeds and their protective effect. Cell Mol Biol Lett 11: 438-448.

Babbar S, Marier JF, Mouksassi MS, Beliveau M, Vanhove GF, Chanda S, Bley K 2009. Pharmacokinetic analysis of capsaicin after topical administration of a highconcentration capsaicin patch to patients with peripheral neuropathic pain. Ther Drug Monit 31: 502-510.
Balogun AM, Fetuga BL 2004.Fatty acid composition of seed oils of some members of the leguminosae family. Food Chem 17: 175-182.

Bender G, Florian JA Jr, Bramwell S, Field MJ, Tan KK, Marshall S, DeJongh J, Bies RR, Danhof M 2010. Pharmacokinetic-pharmacodynamic analysis of the static allodynia response to pregabalin and sildenafil in a rat model of neuropathic pain. J Pharmacol Exp Ther 334: 599-608.

Bennett GJ, Xie YK 1988. A peripheral mononeuropathy in rat that produces disorders of pain sensation like those seen in man. Pain Med 33: 87-107

Boulton AJ, Vinik AI, Arezzo JC, Bril V, Feldman EL, Freeman R 2005. Diabetic neuropathies: a statement by the American Diabetes Association. Diabetes Care 28: 956-962.

Burkill IH 1966.A dictionary of the economic products of the Malay Peninsula Edited by: Ministry of Agriculture (Malaysia). Crown Agents for the colonies London: 839.

Carlton SM, Du J, Tan HY, Nesic O, Hargett GL, Bopp AC, Yamani A, Lin Q, Willis WD, Hulsebosch CE 2009. Peripheral and central sensitization in remote spinal cord regions Contribute to central neuropathic pain after spinal cord injury. Pain 147: 265-276.

Carol W, Jane K 2006. Evidence based treatment of diabetic peripheral neuropathy. J Am Acad Nurse Prac 2: 370378.

Comelli F, Giagnoni G, Bettoni I, Colleoni M, Costa B 2008. Antihyperalgesic effect of a $\mathrm{C}$ annabis sativa extract in 
a rat model of neuropathic pain: mechanisms involved. Phytother Res 8: 1017-1024.

Cui JG, Holmin S, Mathiesen T, Meyerson BA, Linderoth B 2000. Possible role of inflammatory mediators in tactile hypersensitivity in rat models of mononeuropathy. Pain 88: 239-248.

Dwight EM 2006.The clinical management of neuropathic pain. Prog Pain Res Manag 11: 30A-36A.

Ellis RJ, ToperoffW, VaidaF, vanden BrandeG, Gonzales J, Gouaux B, Bentley H, Atkinson JH 2009. Smoked medicinal cannabis for neuropathic pain in HIV: a randomized, crossover clinical trial. Neuropsychopharmacol 34: 672680.

Gao X, Kim HK, Chung JM, Chung K 2007. Reactive oxygen species (ROS) are involved in enhancement of NMDAreceptor phosphorylation in animal models of pain. Pain 131: 262-271.

Garg R, Dehran M 2010. Leprosy: A precipitating factor for complex regional pain syndrome. Minerva Anestesiol 76: 758-760.

Glass JD, Culver DG, Levey AI, Nash NR 2002.Very early activation of $\mathrm{m}$-calpain in peripheral nerve during Wallerian degeneration. J Neurol Sci 196: 9-20.

Goddard M, Zheng Y, Darlington CL, Smith PF 2008. Locomotor and exploratory behavior in the rat following bilateral vestibular deafferentation. Behav Neurosci 122: 448459.

Gordois A, Scuffham P, Shearer A, Oglesby A, Tobian JA 2003. The health care costs of diabetic peripheral neuropathy in the US. Diabetes Care 26: 1790-1795.

Gupta S, Kataria M, Gupta PK, Murganandan S, Yashroy RC 2004. Protective role of extracts of neem seeds in diabetes caused by Strep- tozotocin in rats, $J$ Ethnopharmacol 90: 185-189.

Hama AT, Plum AW, Sagen J 2010. Antinociceptive effect of ambroxol in rats with neuropathic spinal cord injury pain. Pharmacol Biochem Behav 97: 249-255.

Howes FN 1974. A dictionary of useful everyday plants and their common names. Cambridge University Press, 15.

Jain SR 1968. Hypoglycemic principal in the Musa sapeintum and its isolation. Planta Med 1: 43-47.

Jain V, Jaggi AS, Singh N 2009. Ameliorative potential of rosiglitazone in tibialand sural nerve transection-induced painful neuropathy in rats. Pharmacol Res 59: 385-392.

Jones BJ, Roberts DJ 1968. The quantitative measurement of motor incoordination in naïve mice using an accelerating rotarod. J Pharm Pharmacol 20: 302-304.

Kanter M 2008. Effects of Nigella sativa and its major constituent, thymoquinone on sciatic nerves in experimental diabetic neuropathy. Neurochem Res 1: 87-96.

Khare CP 2007. Indian Medicinal Plants - An illustrated Dictionary, Springer-Verlag; Berlin: 601.

Kim YS, Park HJ, Kim TK, Moon DE, Lee HJ 2009. The effects of Ginkgo biloba extract EGb 761 on mechanical and cold allodynia in a rat model of neuropathic pain. Anesth Analg 108: 1958-1963.

Kumar K, Taylor RS, Jacques L, Eldabe S, Meglio M, Molet J, Thomson S, O'Callaghan J, Eisenberg E, Milbouw G, Buchser E, Fortini G, Richardson J, North RB 2007. Spinal cord stimulation versus conventional medical management for neuropathic pain: a multicentre randomised controlled trial in patients with failed back surgery syndrome. Pain 132: 179-188.

Kumar N, Laferriere A, Yu JS, Leavitt A, Coderre TJ 2010. Evidence that pregabalin reduces neuropathic pain by inhibiting the spinal release of glutamate. J Neurochem 113: 552-561.

Lee BH, Won R, Baik EJ, Lee SH, Moon CH 2000. An animal model of neuropathic pain employing injury to the sciatic nerve branches. Neuroreport 11: 657-661.

Lowry OH, Rosenbrough NJ, Farr AL, Randall RJ 1951. Protein measurement with folin phenol reagent. $J$ Biol Chem 193: 265-275.

Marchand F, Perretti M, McMahon SB 2005. Role of immune system in chronic pain. Nat Rev Neurosci 6: 521-532.

Muhammad SA, Farman A, Iqbal A, Muhammad KP 2005. Parvonin: A new Five membered lactone from Adenanthera parvonina Linn. (Mimosaceae). Nat Prod Res 9: 37-40.

Muthuraman A, Diwan V, Jaggi AS, Singh N, Singh D 2008a. Ameliorative effects of Ocimum sanctum in sciatic nerve transection Induced neuropathy in rats. $J$ Ethnopharmacol 120: 56-62.

Muthuraman A, Jaggi AS, Singh N, Singh D 2008b. Ameliorative effects of amiloride and pralidoxime in chronic constriction injury and vincristine induced painful neuropathy in rats. Eur J Pharmacol 587: 104-111.

Muthuraman A, Ramesh M, Sood S 2010a. Development of animal model for vasculatic neuropathy: Induction by ischemic-reperfusion in the rat femoral artery. $J$ Neurosci Meth 186: 215-221.

Muthuraman A, Sood S 2010b. Pharmacological evaluation of tacrolimus (FK-506) on ischemia reperfusion induced vasculatic neuropathic pain in rats. J Brachial Plex Peripher Nerve Inj 5: 13-23.

Nurmikko TJ, Serpell MG, Hoggart B, Toomey PJ, Morlion BJ, Haines D 2007. Sativex successfully treats neuropathic pain characterised by allodynia: a randomised, doubleblind, placebo-controlled clinical trial. Pain 133: 210220.

Olajide AO, Echianu CA, Adedapo AD, Makinde JM 2004. Antiinflammatory studies on Adenanthera pavonina seed extract. Inflammopharmacology 12: 196-202.

Otto M, Bak S, Bach FW, Jensen TS, Sindrup SH 2003. Pain phenomena and possible mechanisms in patients with painful polyneuropathy. Pain 101: 187-192.

Park HJ, Joo HS, Chang HW, Lee JY, Hong SH, Lee Y, Moon DE 2010. Attenuation of neuropathy-induced allodynia following intraplantar injection of pregabalin. Can $J$ 
Attenuating effect of seeds of Adenanthera pavonina aqueous extract in neuropathic pain in streptozotocin-induced diabetic rats: an evidence of

Anaesth 57: 664-671.

Severinghaus JW, Ferrebee JW 1950. Calcium determination by flame photometry; methods for serum, urine, and other fluids. J Biol Chem 187: 621-630.

Shaladi AM, Saltari MR, Crestani F, Piva B 2009. Post-surgical neuropathic pain. Recent Prog Med 100: 371-379.

Sharma SS, Kumar A, Kaundal R 2008. 4-Amino-1,8napthalimide: A potent PARP inhibitor, its neuroprotective role in experimental diabetic neuropathy. Life Sci 82: 570-576.

Sudoh Y, Desai SP, Haderer AE, Sudoh S, Gerner P, Anthony DC, De Girolami U, Wang GK 2004. Neurologic and histopathologic evaluation after high volume intrathecal amitriptyline. Reg Anesth Pain Med 29: 434-440.

Thomas PK 1999. Diabetic peripheral neuropathies: their cost to patient and society and the value of knowledge of risk factors for development of interventions. Eur Neurol 41(Suppl 1): 35-43.

Thomson S, Jacques L 2009. Demographic characteristics of patients with severe neuropathic pain secondary to failed back surgery syndrome. Pain Pract 9: 206-215.

Wang HD, Pagano PJ, Du Y, Cayatte AJ, Quinn MT, Brecher P, Cohen RA 1998. Superoxide anion from the adventitia of the rat thoracic aorta inactivates nitric oxide. Circ Res

\section{2: $810-818$}

Wirth JH, Hudgins JC, Paice JA 2005. Use of herbal therapies to relieve pain: A review of efficacy and adverse effects. Pain Manag Nurs 6: 145-167.

Weisz GM, Houang M, Bogduk N 2010.Complex regional pain syndrome associated with cervical disc protrusion and foraminotomy. Pain 11: 1348-1351.

Woolf CJ, Mannion RJ 1999. Neuropathic pain: aetiology, symptoms, mechanisms, and management. Lancet 353: 1959-1964.

Yadav N, Misra G,.Nigram SK 1976. Triterpenoids from Adenanthera parvonina bark. Plant Methods 29: 176178.

Young W 1992. Role of calcium in central nervous system injuries. J Neurotrauma 9: 9-25.

\section{*Correspondence}

\section{Ramdas B.Pandhare}

Department of Pharmacology, MES College of Pharmacy, Sonai, Newasa, Ahmednagar, Maharashtra-414105, India

ramdaspandhare83@rediffmail.com

Tel. +919881969052

Fax: +91 02427230948 